\title{
THE
}

\section{Age-related inducibility of carboxylesterases by the antiepileptic agent phenobarbital and implications in drug metabolism and lipid accumulation}

\author{
Da Xiao \\ University of Rhode Island \\ Yi-Tzai Chen \\ University of Rhode Island \\ Dongfang Yang \\ University of Rhode Island \\ Bingfang Yan \\ University of Rhode Island, bingfangyan@uri.edu \\ Follow this and additional works at: https://digitalcommons.uri.edu/bps_facpubs \\ This is a pre-publication author manuscript of the final, published article. \\ Creative Commons License \\ c) (†) $\ominus$
}

This work is licensed under a Creative Commons Attribution-Noncommercial-No Derivative Works 4.0 License.

\section{Citation/Publisher Attribution}

Xiao, D., Chen, Y.-T., Yang, D., \& Yan, B. (2012). Age-related inducibility of carboxylesterases by the antiepileptic agent phenobarbital and implications in drug metabolism and lipid accumulation. Biochemical Pharmacology, 84(2), 232-239. doi: 10.1016/j.bcp.2012.04.002

Available at: https://doi.org/10.1016/j.bcp.2012.04.002

This Article is brought to you for free and open access by the Biomedical and Pharmaceutical Sciences at DigitalCommons@URI. It has been accepted for inclusion in Biomedical and Pharmaceutical Sciences Faculty Publications by an authorized administrator of DigitalCommons@URI. For more information, please contact digitalcommons-group@uri.edu. 


\title{
Age-Related Inducibility of Carboxylesterases by the Antiepileptic Agent Phenobarbital and Implications in Drug Metabolism and Lipid Accumulation 1,,2
}

\author{
Da Xiao, Yi-Tzai Chen, Dongfang Yang, and Bingfang Yan \\ Department of Biomedical Sciences, Center for Pharmacogenomics and Molecular Therapy \\ University of Rhode Island Kingston, RI 02881
}

\begin{abstract}
Carboxylesterases (CES) constitute a class of hydrolytic enzymes that play critical roles in drug metabolism and lipid mobilization. Previous studies with a large number of human liver samples have suggested that the inducibility of carboxylesterases is inversely related with age. To directly test this possibility, neonatal (10 days of age) and adult mice were treated with the antiepileptic agent phenobarbital. The expression and hydrolytic activity were determined on six major carboxylesterases including ces1d, the ortholog of human CES1. Without exception, all carboxylesterases tested were induced to a greater extent in neonatal than adult mice. The induction was detected at mRNA, protein and catalytic levels. Ces1d was greatly induced and found to rapidly hydrolyze the antiplatelet agent clopidogrel and support the accumulation of neutral lipids. Phenobarbital represents a large number of therapeutic agents that induce drug metabolizing enzymes and transporters in a species-conserved manner. The higher inducibility of carboxylesterases in the developmental age likely represents a general phenomenon cross species including human. Consequently, individuals in the developmental age may experience greater drug-drug interactions. The greater induction of ces1d also provides a molecular explanation to the clinical observation that children on antiepileptic drugs increase plasma lipids.
\end{abstract}

\section{Introduction}

Carboxylesterases (E.C.3.1.1.1) constitute a class of hydrolytic enzymes that play critical roles in lipid mobilization [1], drug metabolism [1-3] and detoxification of organophosphorus, carba-mate and pyrethroid insecticides [4, 5]. Those are major insecticides used in agricultural and residential setting [6]. Based on chemical structures, it

\footnotetext{
${ }^{1}$ This work was supported by NIH grants R01GM61988 and R01ES07965.

${ }^{2}$ To whom correspondence should be addressed.

() 2012 Elsevier Inc. All rights reserved.

Address Correspondence to: Dr. Bingfang Yan, Department of Biomedical and Pharmaceutical Sciences, University of Rhode Island, Kingston, RI 02881, Phone: (401) 874-5032, Fax: (401) 874-5048, byan@uri.edu.

${ }^{4}$ The authors indicate no potential conflict of interest.

Publisher's Disclaimer: This is a PDF file of an unedited manuscript that has been accepted for publication. As a service to our customers we are providing this early version of the manuscript. The manuscript will undergo copyediting, typesetting, and review of the resulting proof before it is published in its final citable form. Please note that during the production process errors may be discovered which could affect the content, and all legal disclaimers that apply to the journal pertain.
} 
is estimated that $\sim 20 \%$ therapeutic agents undergo hydrolytic biotransformation [3].

Carboxylesterase activity is widely distributed in mammalian tissues, with the highest level in liver microsomes. Without exceptions, all mammalian species express multiple forms of carboxylesterases [7]. However, the total number of carboxylesterase genes varies markedly from species to species. For example, the human genome has seven carboxylesterase genes including a pseudogene $[7,8]$, whereas the mouse genome contains as many as twenty carboxylesterase genes [7]. In addition, diverse forms of carboxylesterases from a single gene are produced through mechanisms such as alternative splicing [2].

Like many other drug-metabolizing enzymes, the expression of carboxylesterases is regulated by age, hormones, disease mediators and therapeutic agents [5, 9-12]. For example, interleukin-6, a proinflammatory cytokine, suppresses the expression of several human carboxylesterases [9]. Likewise, lipopolysaccharide, a potent proinflammatory stimulus, efficaciously down-regulates the expression of several mouse carboxylesterases [13]. Importantly, the suppressed expression by inflammatory mediators causes profound changes in cellular responsiveness to commonly used ester drugs. For example, pretreatment with interleukin-6 significantly decreases the hydrolytic activation of the anticancer prodrug irinotecan [9]. In some cases, the regulated expression of carboxylesterases occurs in a species-dependent manner. For example, the synthetic glucocorticoid dexamethasone slightly induces human carboxylesterases but suppresses several major rat carboxylesterases [10]. Conversely, phenobarbital, an antiepileptic agent, induces carboxylesterases cross species $[14,15]$.

The regulation of carboxylesterase expression, in many cases, is likely achieved by composite mechanisms. In both human and rodents, we have shown that age is a major determinant in gaining hydrolytic capacity during the developmental stage [5, 11, 14]. In humans, the developmental regulation consists of an early surge during the neonatal stage and a subsequent incremental increase throughout the entire adolescence. Interestingly, it has been reported that some ester drugs exhibit larger pharmacokinetic variation among young patients [16-18]. The greater variability is likely attributed to interplay between developmental and xenobiotic regulations. In support of this notion, the level of carboxylesterases is correlated with age but only to a moderate extent $[5,11]$ and several major antiepileptic drugs including pheno-barbital increased the hydrolysis of rufinamide to a greater extent in children than adults [17].

This study was designed to test the hypothesis that the inducibility of carboxylesterases is inversely related with age. To test this hypothesis, neonatal (10 days of age) and adult (10 weeks) mice were treated with phenobarbital and the expression of six major carboxylesterases was determined. Without exceptions, phenobarbital caused greater induction of carboxylesterases in neonatal mice. The induction was detected by RT-qPCR and Western blotting. The induced carboxylesterases differed markedly in the hydrolysis of several commonly used drugs and in the accumulation of neutral lipids. 


\section{Materials and Methods}

\subsection{Chemicals and supplies}

Aspirin, 1,4-Bis[2-(3,5-dichloropyridyloxy)]benzene (TCPOBOP), 4methylumbelliferylacetate, 1-naphthylacetate, Oil Red O, pregnenolone 16a-carbonitrile (PCN) and Hanks balanced salt solution were purchased from Sigma (St. Louis, MO). Clopidogrel bisulfate was purchased from ChemPacific (Baltimore, MD). Clopidogrel carboxylate was purchased from Toronto Research Chemicals (Toronto, ON, Canada). Dulbecco's modified eagle medium (DMEM) was purchased from Invitrogen (Carlsbad, CA). The antibody against glyceradehyde-3-phosphate dehydrogenase (gapdh) was from Abcam (Cambridge, UK). The goat anti-rabbit IgG conjugated with horseradish peroxidase was from Pierce (Rockford, IL). Nitrocellulose membranes were from Bio-Rad (Hercules, CA). Expression constructs were purchased from OriGene Technologies Inc (Rockville, MD). Unless otherwise specified, all other reagents were purchased from Fisher Scientific (Fair Lawn, NJ).

\subsection{Animal treatment}

Mice (C56BL/6) were purchased from Charles River (Wilmington, MA) and bred in house. Male neonates (10 days of age) or adult (10 weeks of age) were injected $i p$ once daily with phenobarbital or the same volume of saline for four days [19]. Neonates received phenobarbital at a dose of $20 \mathrm{mg} / \mathrm{kg} / \mathrm{day}$, whereas adult mice received a dose of $80 \mathrm{mg} / \mathrm{kg} /$ day. For TCРОВOP treatment, all mice received $1.5 \mathrm{mg} / \mathrm{kg} / \mathrm{day}$ for consecutive four days. For PCN, all mice received $20 \mathrm{mg} / \mathrm{kg} /$ day for consecutive four days. The livers were harvested $24 \mathrm{~h}$ after the last injection. One part of the livers was immediately used for preparing total RNA and the remaining part was frozen at $-80^{\circ} \mathrm{C}$ for preparing $\mathrm{S} 9$ fractions later. All mice were allowed free access to Purina Rodent Chow 5001 and water, and the use of animals was approved by the Institutional Animal Care and Use Committee.

\subsection{Native gel electrophoresis stained for carboxylesterase activity}

The mouse genome contains three times of carboxylesterase genes as the human genome [7]. There are no specific substrates for each carboxylesterase. We have previously shown that many carboxylesterases remain active in polyacrylamide gel [12]. Importantly, carboxylesterases, even hydrolyzing the same substrate, can be electrophoretically separated and individually determined for hydrolytic activity. Liver homogenates $(10 \mu \mathrm{g})$ was solubilized with $0.2 \%$ Lubrol and subjected to electrophoresis with a $3 \%$ acrylamide stacking gel and a 7.5\% acrylamide separating gel. After electrophoresis, the gels were washed for $1 \mathrm{~h}$ in $100 \mathrm{mM}$ potassium phosphate buffer ( $\mathrm{pH}$ 6.5), followed by incubating in the same buffer containing 1-naphthylacetate $(5 \mathrm{mM})$ and 4-benzolamino-2,5dimethoxybenzenediazonium chloride hemi (zinc chloride) salt, usually termed Fast Blue $\mathrm{RR}(0.4 \mathrm{mg} / \mathrm{ml})$. Staining for carboxylesterases by this method is based on the formation of a black, insoluble complex between the hydrolytic products and Fast Blue RR. Staining for hydrolytic activity was also determined with 4-methylumbelliferylacetate (1 mM). In both cases, the images were captured by Carestream 2200 PRO Imager. 


\subsection{Reverse transcription-quantitative polymerase chain eaction (RT-qPCR)}

Total RNA ( $1 \mu \mathrm{g})$ was reverse-transcribed to synthesize cDNAs as described previously [11]. cDNAs were then diluted 16 times and RT-qPCR was conducted with TaqMan Gene Expression Assay (Applied Biosystems, Foster City, CA). The TaqMan probes were: ces1d (Ces3), Mm00474816_m1; ces1e (Es22), Mm00504914_m1; ces1g (ces1), Mm00491334_m1; ces2a (Ces6), Mm00731842_g1; ces2c (Ces2), Mm00524035_m1, and ces2e (Ces5), Mm00555211_m1. Normalization of RT-qPCR was performed based on the signal of gapdh mRNA (Mm99999915_g1); and selective samples were analyzed for the level of RNA polymerase II mRNA (Mm00839502_m1) to confirm the normalization. The PCR amplification was conducted in a total volume of $20 \mu$ containing universal PCR master mixture $(10 \mu \mathrm{l})$, gene-specific TaqMan assay mixture ( $1 \mu \mathrm{l})$, and cDNA template (6 $\mu \mathrm{l})$. Amplification and quantification were done with the Applied Biosystems 7500 RealTime PCR System.

\subsection{Hydrolysis of 1-naphthylacetate, aspirin and clopidogrel}

Hydrolysis of 1-naphthylacetate was determined spectrophotometrically as described previously [8]. Hydrolysis of aspirin and clopidogrel was determined as described elsewhere [20]. Briefly, samples $(20 \mu \mathrm{g})$ were prepared in $50 \mu \mathrm{l}$ phosphate buffer $(0.1 \mathrm{M}, \mathrm{pH} 7.4)$ and then mixed with an equal volume of aspirin (usually $2 \mathrm{mM}$ ) in the same buffer. The incubations lasted for $30 \mathrm{~min}$ and the reactions were terminated with $150 \mu \mathrm{l}$ of acetonitrile containing acetaminophen $(5 \mathrm{mM})$ as the internal standard (IS). The reaction mixtures were subjected to centrifugation for $15 \mathrm{~min}$ at $4^{\circ} \mathrm{C}(12,000 \mathrm{~g})$. Hydrolysis of clopidogrel was carried similarly as that of aspirin. Samples $(20 \mu \mathrm{g})$ were prepared in $50 \mu \mathrm{l}$ reaction buffer Tris- $\mathrm{HCl}(50 \mathrm{mM}, \mathrm{pH} 7.4)$, mixed with an equal volume of clopidogrel $(200 \mu \mathrm{M})$ in the same buffer, and incubated at $37^{\circ} \mathrm{C}$ for $20 \mathrm{~min}$. The reactions were terminated and centrifuged as described for the hydrolysis of aspirin, however, naproxen $(0.5 \mathrm{mM})$ served the IS. The formation of the hydrolytic metabolites was determined by HPLC (Hitachi-300) with a Chromolith SpeedROD column RP-18e (Merck, Germany). The supernatants (10-30 $\mu \mathrm{l})$ of the reaction mixtures were injected and separated by an isocratic (for aspirin) or gradient (clopidogrel) mobile phase. The isocratic mobile phase consisted of $12 \%$ methanol and $0.25 \%$ acetate acid at $\mathrm{pH} 3.9$. The gradient mobile phase consisted of $4-21 \%$ acetonitrile (v/v) for the first $4 \mathrm{~min}$ and $2-70 \%$ for second $4 \mathrm{~min}$. The flow rate for both aspirin and clopidogrel was $2 \mathrm{ml} / \mathrm{min}$ and the metabolites were detected by a diode array detector at $238 \mathrm{~nm}$ (salicylic acid) or $230 \mathrm{~nm}$ (clopidogrel carboxylate). All quantifications were performed using peak area ratios and calibration curves generated from the corresponding internal control.

\subsection{Oil Red O staining}

Cells (293T) from GenHunter Corporation (Nashville, TN) were transfected with a construct encoding a mouse carboxylesterase or the corresponding vector. The transfected cells were cultured in full DMEM medium for $24 \mathrm{~h}$ and then in fatty acid-rich but serum free medium (BSA complexed palmitic acid, $0.2 \mathrm{mM}$ ) for $24 \mathrm{~h}$. Cells were washed extensively PBS and fixed with $4 \%$ paraformaldehyde for $20 \mathrm{~min}$ at room temperature. The fixed cells underwent dehydration with $100 \%$ 1,2-propanediol, stained with pre-warmed Oil Red $\mathrm{O}$ for $1 \mathrm{~h}$ at $37^{\circ} \mathrm{C}$ 
and rinsed with 85\% 1,2-propanediol. The cells were washed with distilled water and visualized for red fluorescence microscopically. Alternatively, stained lipids were extracted with isopropyl alcohol, and quantified spectrometrically at $510 \mathrm{~nm}$.

\subsection{Other analyses}

Protein concentrations were determined with BCA assay (Pierce) based on albumin standard. Western blotting was performed as described previously [11] and the preparation of antibodies were described elsewhere [15]. Data are presented as mean $\pm \mathrm{SD}$ or mean $\pm \mathrm{SE}$ of at least three separate experiments, except where results of blots are shown in which case a representative experiment is depicted in the figures. Statistical significance between two means was made according to One-way ANOVA followed by a DUNCAN's multiple comparison test $(p<0.05)$. Letters or lines combined with asterisks were used to indicate data-points for the comparisons.

\section{Results}

\subsection{Induction of carboxylesterases in neonates and adult mice}

In this study, we first tested whether neonates (10-day-old) and adult mice show similar levels of induction of carboxylesterases and whether the induction occurs in an isoformdependent manner. Adult mice were dosed at 20 or $80 \mathrm{mg} / \mathrm{kg} /$ day whereas neonates were given three dosing regimens: 20,40 , or $80 \mathrm{mg} / \mathrm{kg} /$ day. However, some or all neonates were dead at higher dosing regimens. Adult mice, dosed at $20 \mathrm{mg} / \mathrm{kg} / \mathrm{day}$, did not cause evident induction on the carboxylesterases examined. Therefore, the results were presented from neonates treated with the $20 \mathrm{mg} / \mathrm{kg} /$ day regimen and adult mice treated with the 80 $\mathrm{mg} / \mathrm{kg} /$ day dosing regimen. The induction was initially assessed by native gel electrophoresis stained for carboxylesterase activity with 1-naphthylacetate or 4methylumbelliferylacetate as the substrate. To gain the molecular identity, six recombinant mouse carboxylesterases were included in this study and used as references [1, 7, 14, 21]. As shown in Fig. 1A (Left), carboxylesterases stained with 1-naphthylacetate detected recombinant ces1d, ces1e, ces2c and ces2e (Fig. 1A). Ces1d produced the maximal staining followed by ces2c, ces1e and ces2e. With 4-methylumbelliferylacetate as the substrate, four recombinant carboxylesterases were detected as well (Fig. 1B). However, there were notable differences. Ces1e hydrolyzed 1-naphthylacetate but not 4-methylumbelliferylacetate, and the opposite was true with ces2a (Figs. 1A and B). In addition, ces $2 \mathrm{c}$ showed higher activity toward 4-methylumbelliferylacetate than ces1d, and this was reversed when 1naphthylacetate was used as the substrate. Interestingly, ces1g did not hydrolyze either substrate. As described later, transfection of this carboxylesterase did produce a protein detected by Western blotting.

Liver S9 fractions from adult mice produced seven recognizable bands and four of them corresponded to ces1d, ces2a, ces2e and ces2c, respectively (Fig. 1). It appeared that ces1d produced two closely migrated bands (upper and lower), although it can not be excluded that these two bands represent distinct carboxylesterases. Nevertheless, the lower band was more intensified than the upper band with 4-methylumbelliferylacetate as the substrate (Fig. 1B) but the opposite was true when 1-naphthylacetate (Fig. 1A). Ces2c was markedly induced 
with both substrates in phenobarbital-treated adult mice. However, ces $1 \mathrm{~d}$ and one of the identity-unknown bands (ces-x) were also evidently induced when 1-naphthylacetate was used as the substrate (Fig. 1A). In contrast to the adult liver samples, neonatal samples produced only three recognizable bands including ces $1 \mathrm{~d}$, ces- $\mathrm{x}$ and ces $2 \mathrm{c}$. All of these carboxylesterases were markedly induced by both substrates. Overall, the activity staining experiments demonstrated that neonates, compared with adult mice, expressed lower levels and fewer carboxylesterases. However, the magnitude of induction in neonates was generally greater than that in adult mice, which was confirmed by Western blotting and RTqPCR as described below. Finally, ces1e was not detected in either neonatal or adult mouse livers by the staining experiment, suggesting that this carboxylesterase does not hydrolyze 4methylumbelliferyl-acetate or 1-naphthylacetate (Fig. 1).

It is well established that two major nuclear receptors supports the action of phenobarbital: the constitutive androstane receptor and the pregnane $\mathrm{X}$ receptor [22]. To shed light on the identity of the receptor(s) in supporting the induction of carboxylesterases by phenobarbital, mice (neonatal and adult) were treated with receptor-specific activator and the induction was determined. TCPOBOP was used as the specific activator for the constitutive androstane receptor and PCN for the pregnane $\mathrm{X}$ receptor. As shown in Fig. 1C, PCN generally induced carboxylesterases to a greater extent than TCPOBOP (TCP) in neonatal mice with an exception of ces2c. In adult mice, ces1d was induced to a slightly higher extent by TCP whereas ces2e was induced to a slightly greater extent by PCN. Interestingly, TCP caused much higher induction of ces $2 \mathrm{c}$ than PCN in adult mice (Fig. 1C). These results suggest that the magnitude of induction varies depending on age, receptor or a particular form of carboxylesterases.

\subsection{Isoform-specific induction of carboxylesterases at mRNA level}

We next tested whether the induction on the activity reflects increases of carboxylesterase mRNA. Without exceptions, treatment with phenobarbital significantly increased the mRNA levels of all six carboxylesterases in neonates (2.4- to 14.7-fold) (Fig. 2). In contrast, only four of them were significantly induced in adult mice with the 4.9-fold induction being the highest. Among all carboxylesterases, the magnitude of induction was greater in neonatal than adult mice. At the basal levels, all carboxylesterases had higher levels of mRNA in adult than neonatal mice with an exception of ces $2 \mathrm{e}$. The mRNA level of this carboxylesterase in adult mice was lower than that in neonates, consistent with the activity staining, particularly with 4-methylumbelliferylacetate as the substrate (Fig. 1). Based on the $\mathrm{Ct}$ values (threshold cycles), the relative level of mRNA among these carboxylesterases from the least to most abundance was: ces2c (30.2), ces1g (24.6), ces1e (24.3), ces2a (23.8), ces1d (23.2) and ces2e (23.0) at basal expression.

\subsection{Immunoreactivity of mouse carboxylesterases}

We next examined whether the induction of mRNA translates into increases of protein. This was determined by Western blotting. We did not have antibodies against all six carboxylesterases. However, we raised several antibodies against human or rat carboxylesterases in the past [15], and some of them were found to have high crossreactivity with other carboxylesterases $[21,23]$. These antibodies were used to determine the 
levels of mouse liver carboxylesterases with recombinant enzymes as controls. As shown in Fig. 3A, anti-human CES1 strongly cross-reacted with Ces1d. Anti-human CES2 strongly cross-reacted with ces1e, modestly with ces $2 \mathrm{a}$ and slightly with ces2e. These carboxylesterases were electrophoretically distinct. As expected, anti-mouse ces1d showed no cross-activity with other five carboxylesterases. Anti-rat ces1d strongly cross-reacted with mouse ces1d and slightly with ces1g. Anti-rat ces1f slightly cross-reacted with mouse ces1e. Anti-rat Ces1c strongly cross-reacted with ces1d and 1e, which were electrophoretically distinct (Fig. 3A).

As for the liver samples, anti-human CES1 detected two bands with the dominant band comigrating with ces1d (Fig. 3A). Based on the relative immune-staining, neonatal samples showed a 1.96-fold induction whereas adult samples showed a 1.26-fold induction. Antihuman CES2 did not detect any carboxylesterases in liver samples, although this antibody strongly cross-reacted with ces1e. Anti-mouse ces1d and anti-rat Ces1d detected similar changes in neonates and adult as anti-human CES1 antibody. In contrast, anti-rat ces1f detected a dominant carboxylesterase in adult but not neonatal samples, and this carboxylesterase appeared not to be induced by phenobarbital. Anti-rat Ces1c antibody detected a 2.26-fold induction of a carboxylesterase co-migrating with ces1d in neonatal samples, but the same enzyme was induced by only 1.24 fold in adult samples. Clearly, the Western blotting demonstrated that ces1d was induced to a higher extent in neonatal than adult samples. Previously we have shown that human CES1, generally considered the ortholog of mouse ces1d, hydrolyzed the antiplatelet agent clopidogrel but not aspirin [20]. To confirm whether greater induction of ces1d translates into higher hydrolytic activity by neonatal samples, hydrolysis of clopidogrel and aspirin was determined. As shown in Fig. 3B, phenobarbital $(\mathrm{PB})$ treatment significantly increased the hydrolysis of both agents by neonatal samples. However, adult samples showed significant increases only in the hydrolysis of clopidogrel. This increase was much higher in neonatal than adult samples (5.8- versus 1.3-fold) (Fig. 3B).

\subsection{Lipid accumulation and hydrolysis of aspirin, clopidogrel and 1-naphthylacetate}

As discussed above, the mouse genome has almost three times of the number of carboxylesterase genes of the human genome [7]. It is conceivable that many mouse carboxylesterases may share substrate specificity. To shed light on this possibility, lysates from cells transfected with one of the six carboxylesterases was tested for the hydrolysis of aspirin, clopidogrel and 1-naphythylacetate. As shown in Fig. 4A, transfection of ces2c and ces $2 \mathrm{e}$ but not others led to large increases in the hydrolysis of aspirin compared with vector transfection. In contrast, transfection of ces1d but not others markedly increased the hydrolysis of clopidogrel (Fig. 4B). Transfection of ces2c greatly increased the hydrolysis of 1-naphythylacetate (Fig. 4C). It should be noted that transfection of all carboxylesterases, compared with vector transfection, caused statistically significant increases in the hydrolysis of all three substrates. Several carboxylesterases, notably ces1d, were shown to hydrolyze triglyceride [1]. To test this possibility, transfected cells were cultured in fatty acid-rich medium and the lipid accumulation was determined by Oil Red O staining [24, 25]. As shown in Fig. 5, transfection with ces1d but not others significantly increased the staining intensity. This was surprising as ces1d is generally considered to hydrolyze triglyceride [1], 
thus favoring lipid elimination from cells. The same observation was made by microscopic analysis (Right of Fig. 5). These results suggest that ces1d likely catalyzes synthesis of triglyceride in fatty acid-rich condition.

\section{Discussion}

Hydrolytic metabolism is a major pharmacokinetic determinant of drugs containing such functional groups as carboxylic acid ester, thioester and amide [2, 26, 27]. Previous studies from this laboratory have suggested that both developmental and xenobiotic regulations are involved in the expression of carboxylesterases [5, 11]. In this study, we tested the inducibility of several major mouse carboxylesterases as a function of age: neonatal and adult mice. The magnitude of the induction in neonates by phenobarbital was consistently greater than that in their adult counterparts. In addition, the overall inducibility among carboxylesterases varied markedly at mRNA level. The induction led to marked increases in the hydrolysis of drugs such as clopidogrel, a widely used antiplatelet agent [19].

The greater induction of carboxylesterases by phenobarbital during the developmental stage likely represents a general phenomenon among various species. In rats, phenobarbital induced several cytochrome P450 enzymes, however, the magnitude of the induction was much higher in neonatal than adult animals [28]. Rufinamide, an antiepileptic agent, was approved for treating seizures with Lennox-Gastaut syndrome in combination with other antiepileptic drugs including phenobarbital [17]. Rufinamide caused little pharmacokinetic changes in co-administered drugs, however, some of the co-administered drugs including phenobarbital markedly decreased the plasma level of rufinamide [17]. The decrease in pediatric patients was almost twice of that in adults. Given the fact that rufinamide undergoes extensive hydrolytic metabolism, the greater decrease in pediatric patients is likely due to greater induction of carboxylesterase, presumably CES1. On the other hand, hydrolysis by carboxylesterases results in the formation of an alcohol and an acid [20,29]. In many cases, the acid is removed by member-bound transporters. As a result, the elimination of hydrolytic metabolites of drugs may vary depending on the relative changes of the activities of particular transporters [30]. Interestingly, phenobarbital has been shown to induce many transporters as well [31].

In addition to a greater significance in drug-drug interactions, higher magnitude of induction in children or young animals may have a greater effect on the development of metabolic diseases. Many carboxylesterases are shown to hydrolyze lipids, presumably leading to increased elimination of cellular lipids. Indeed, stable transfection of ces1g significantly decreased the cellular accumulation of triglycerides [32]. Consistently, overexpression of human CES1 through adenoviral transduction increased biliary elimination of cholesterol [33]. On the other hand, knockout of ces1d, a major hydrolase of triglycerides, did not increase steatotic phenotypes in the liver [34]. Likewise, transgenic expression of human CES1 led to worsening lipid profile [35]. Clearly, more robust experimental approaches should be taken to clarify these discrepancies. Nevertheless, many antiepileptic drugs including phenobarbital were found to increase plasma total cholesterol and low-densitylipoprotein cholesterol in children [36]. Interestingly, the increase was not observed with valproic acid, also a commonly used antiepileptic drug [37]. Valproic acid was recently 
found to inhibit human CES1 [37], pointing to an involvement of CES1 induction in the increased plasma lipids.

Phenobarbital is the most used antiepileptic worldwide [38] and represents the prototype of a large number of structurally diverse inducers, commonly referred as to phenobarbital-type inducers [39-41]. This antiepileptic exerts pharmacological activity by acting on the $\gamma$ aminobutyric acid receptors [38]. However, induction of drug-metabolizing enzymes and transporters by phenobarbital is largely mediated through the activation of the constitutive androstane receptor or the pregnane X receptor $[22,40]$. These receptors are DNA sequencespecific transcription factors and share DNA binding activity to some extent. Nevertheless, the study with receptor-specific activator suggested that both receptors likely support the induction in response to phenobarbital but their involvement may varies depending on age and the form of carboxylesterases (Fig. 1C). It should be noted that the inducibility of each carboxylesterase was not necessarily associated with low basal level expression. For example, ces1e and ces1g have similar basal expression based on the $\mathrm{Ct}$ values (24.3 versus 24.6), but a 2-fold induction was detected on ces1, whereas a 12 -fold induction on ces $1 \mathrm{~g}$ (Fig. 2). These findings suggest that phenobarbital uses multiple mechanisms (receptors) to confer induction of carboxylesterases, and these mechanisms may not be equally involved in the induction among various carboxylesterases.

It was interesting to notice that carboxylesterases with a similar sequence identity did not share similar substrate specificity. For example, ces1d, ces1e and ces1g share a sequence identity of 74-78\%, ces1d but not other two was highly active toward clopidogrel (Fig. 4B). One explanation was the lower expression of cesle and ces1g compared with ces1d. This might not be true with ces1e as considerable expression of this carboxylesterase was detected by Western blotting (Fig. 3A), although the immunostaining intensity on various carboxylesterases depended on the relative affinities toward a cross-reactive antibody. Likewise, ces $2 \mathrm{a}$, ces $2 \mathrm{c}$ and ces $2 \mathrm{e}$ share a sequence identity of $66-70 \%$, and yet, only ces $2 \mathrm{c}$ and ces2e but not ces2a were highly active toward aspirin (Fig. 4A). Interestingly, ces2c was highly induced by phenobarbital (Figs. 1 and 2E), but yet the hydrolysis of aspirin by lysates from phenobarbital-treated mice was increased to a modest extent only (Left of Fig. 3B). One explanation is that ces2c is one of many carboxylesterases with high aspirin hydrolytic activity but other aspirin carboxylesterases were induced insignificantly. Nevertheless, the substrate-specific experiment established that ces1d is highly active toward clopidogrel, ces $2 c$ and ces $2 \mathrm{e}$ are highly active toward aspirin and ces $2 \mathrm{c}$ is highly active toward 1naphthylacetate (Fig. 4). We and other investigators have previously reported that human CES1 preferably hydrolyze ester with an acid moiety relatively larger than the alcohol moiety and the opposite is true with human CES2 [19, 27, 43]. In this regard, mouse ces1d belongs to CES1 type of carboxylesterases, whereas ces2c and ces2e belong to CES2 type of enzymes.

In summary, we have shown that inducibility of carboxylesterases was inversely related with age. The higher induction translated into greater increases in the hydrolysis of commonly used drugs. While this study used mouse as the model, the conclusions made in this report are likely applicable to other species including humans. Phenobarbital induces many drugmetabolizing enzymes in a species-conserved manner, and we have shown that this 
antiepileptic drug induced human carboxylesterases in adult primary hepatocytes [15]. These findings were also supported by clinical observations that drugs belonging to phenobarbitaltype inducers caused greater increases in the clearance of rufinamide and plasma lipids in children. Overall, this study concludes that individuals in the developmental age experiences greater changes in drug metabolism and lipid catabolism due to induction of carboxylesterases.

\section{Acknowledgments}

3 The authors thank Dr. Robert Rodgers of the University of Rhode Island for critical reading ot the manuscript.

\section{References}

1. Quiroga AD, Lehner R. Role of endoplasmic reticulum neutral lipid hydrolases. Trends Endocrinol Metab. 2011; 22:218-225. [PubMed: 21531146]

2. Sanghani SP, Sanghani PC, Schiel MA, Bosron WF. Human carboxylesterases: an update on CES1, CES2 and CES3. Protein Pept Lett. 2009; 16:1207-1214. [PubMed: 19508181]

3. Top 200 http://www.pharmacytimes.com/publications/issue/2011/May2011/Top-200-Drugsof-2010.

4. Dettbarn WD, Yang ZP, Milatovic D. Different role of carboxylesterases in toxicity and tolerance to paraoxon and DFP. Chem Biol Interact. 1999; 119-120:445-454. [PubMed: 10421482]

5. Yang D, Pearce R, Wang X, Roger Gaedigk, Wan YJY, Yan B. Human carboxylesterases HCE1 and HCE2: Ontogenic expression, inter-individual variability and differential hydrolysis of oseltamivir, aspirin, deltamethrin and permethrin. Biochem Pharmacol. 2009; 77:238-247. [PubMed: 18983829]

6. Pérez JJ, Williams MK, Weerasekera G, Smith K, Whyatt RM, Needham LL, Barr DB. Measurement of pyrethroid, organophosphorus, and carbamate insecticides in human plasma using isotope dilution gas chromatography-high resolution mass spectrometry. J Chromatogr B Analyt Technol Biomed Life Sci. 2010; 878:2554-2562.

7. Holmes R, Wright M, Laulederkind S, Cox L, Hosokawa M, Imai T, Ishibashi S, Lehner R, Miyazaki M, Potter P, Redinbo M, Robert J, Satoh T, Yamashita T, Yan B, Yokoi T, RudolfZechner R, Maltais L. Recommended Nomenclature for Five Mammalian Carboxylesterase Gene Families: Human, Mouse and Rat Genes and Proteins. Mammalian Genome. 2010; 21:427-441. [PubMed: 20931200]

8. Yan B, Matoney L, Yang D. Human carboxylesterases in term placentae: enzymatic characterization, molecular cloning, and evidence for the existence of multiple forms. Placenta. 1999; 20:599-607. [PubMed: 10452915]

9. Yang J, Shi D, Yang D, Song X, Yan B. Interleukin-6 alters the cellular responsiveness to clopidogrel, irinotecan, and oseltamivir by suppressing the expression of carboxylesterases HCE1 and HCE2. Mol Pharmacol. 2007; 72:686-694. [PubMed: 17537833]

10. Shi D, Yang J, Yang D, You L, Yan B. Dexamethasone suppresses the expression of multiple rat carboxylesterases through transcriptional repression: evidence for an involvement of the glucocorticoid receptor. Toxicology. 2008; 254:97-105. [PubMed: 18938207]

11. Shi D, Yang D, Prinssen EP, Brian E, Davies BE, Yan B. Surge in expression of carboxylesterase-1 during the post-natal stage enables a rapid gain of the capacity to activate the anti-influenza prodrug oseltamivir. J Infect Dis. 2011; 203:937-942. [PubMed: 21402544]

12. Yang D, Yang J, Shi D, Black C, Deng R, Yan B. Hypolipidemic agent Zguggulsterone: metabolism interplays with induction of cholesteryl ester hydrolase CES1 and bile salt export pump. J Lipid Res. 2012; 53:529-539. [PubMed: 22246918]

13. Mao Z, Li Y, Peng Y, Luan X, Gui H, Feng X, Hu G, Shen J, Yan B, Yang J. Lipopolysaccharide down-regulates carboxylesterases 1 and 2 and reduces hydrolysis activity in vitro and in vivo via p38MAPK-NF- B pathway. Toxicol Lett. 2011; 201:213-220. [PubMed: 21237253] 
14. Morgan EW, Yan B, Greenway D, Parkinson A. Regulation of two rat liver microsomal carboxylesterase isozymes: species differences, tissue distribution and the effects of age, sex and xenobiotic treatment of rats. Arch Biochem Biophys. 1994; 315:514-526.

15. Zhu W, Song L, Zhang H, Matoney L, LeCluyse E, Yan B. Dexamethasone differentially regulates the expression of carboxylesterase genes in humans and rats. Drug Metab Dispos. 2000; 28:186191. [PubMed: 10640517]

16. Oo C, Hill G, Dorr A, Liu B, Boellner S, Ward P. Pharmacokinetics of anti-influenza prodrug oseltamivir in children aged 1-5 years. Eur J Clin Pharmacol. 2003; 59:411-415. [PubMed: 12910331]

17. Perucca E, Cloyd J, Critchley D, Fuseau E. Rufinamide: clinical pharmacokinetics and concentration-response relationships in patients with epilepsy. Epilepsia. 2008; 49:1123-1141. [PubMed: 18503564]

18. Yokoi T. Essentials for starting a pediatric clinical study (1): Pharmacokinetics in children. J Toxicol Sci. 2009; 34(Suppl 2):SP307-312. [PubMed: 19571484]

19. Zhang H, LeCluyse E, Liu L, Hu M, Matoney L, Zhu W, Yan B. Rat pregnane X receptor: molecular cloning, tissue distribution and xenobiotic regulation. Arch Biochem Biophys. 1999; 368:14-22. [PubMed: 10415106]

20. Tang M, Mukundan M, Yang J, Charpentier N, LeCluyse EL, Black C, Yang D, Shi D, Yan B. Anti-platelet agents aspirin and clopidogrel are hydrolyzed by distinct carboxylesterases and clopidogrel is transesterificated in the presence of ethyl alcohol. J Pharmacol Exp Ther. 2006; 319:1467-1476. [PubMed: 16943252]

21. Xie M, Yang D, Wu M, Xue B, Yan B. Mouse liver and kidney carboxylesterase (MLK) rapidly hydrolyzes antitumor prodrug irinotecan and the $\mathrm{N}$-terminal three quarter sequence determines substrate selectivity. Drug Metab Dispos. 2003; 31:21-27. [PubMed: 12485949]

22. Kakizaki S, Takizawa D, Tojima H, Horiguchi N, Yamazaki Y, Mori M. Nuclear receptors CAR and PXR; therapeutic targets for cholestatic liver disease. Front Biosci. 2011; 17:2988-3005.

23. Yan B, Yang D, Bullock P, Parkinson A. Rat serum carboxylesterase: cloning, expression, regulation and evidence of secretion from liver. J Biol Chem. 1995; 270:19128-19134. [PubMed: 7642579]

24. Wang G, Fu Y, Xu W, Feng Y, Fang S, Zhou X. Resveratrol inhibits the expression of SREBP1 in cell model of steatosis via Sirt1-FOXO1 signaling pathway. Biochem and biophysi Res Communi. 2009; 380:644-649.

25. Wu D, Wang X, Zhou R, Cederbaum A. CYP2E1 enhances ethanol-induced lipid accumulation but impairs autophaghy in HepG2 E47 cells. Biochem and biophysi Res Communi. 2010; 402:116122.

26. Satoh T, Hosokawa M. Structure, function and regulation of carboxylesterases. Chem Biol Interact. 2006; 162:195-211. [PubMed: 16919614]

27. Zhu HJ, Appel DI, Johnson JA, Chavin KD, Markowitz JS. Role of carboxylesterase 1 and impact of natural genetic variants on the hydrolysis of trandolapril. Biochem Pharmacol. 2009; 77:12661272. [PubMed: 19185566]

28. Shimada M, Nagata K, Murayama N, Yamazoe Y, Kato R. Role of growth hormone in modulating the constitutive and phenobarbital-induced levels of two P-450(6)beta (testosterone 6 betahydroxylase) mRNAs in rat livers. J Biochem. 1989; 106:1030-1034. [PubMed: 2628419]

29. Shi D, Yang J, Yang D, LeCluyse EL, Black C, You L, Akhlaghi F, Yan B. Anti-influenza prodrug oseltamivir is activated by carboxylesterase HCE1 and the activation is inhibited by anti-platelet agent clopidogrel. J Pharmacol Exp Ther. 2006; 319:1477-1484. [PubMed: 16966469]

30. Morimoto K, Kishimura K, Nagami T, Kodama N, Ogama Y, Yokoyama M, Toda S, Chiyoda T, Shimada R, Inano A, Kano T, Tamai I, Ogihara T. Effect of milk on the pharmacokinetics of oseltamivir in healthy volunteers. J Pharm Sci. 2011; 100:3854-3861. [PubMed: 21607954]

31. Benoki S, Yoshinari K, Chikada T, Imai J, Yamazoe Y. Transactivation of ABCG2 through a novel cis-element in the distal promoter by constitutive androstane receptor but not pregnane $\mathrm{X}$ receptor in human hepatocytes. Arch Biochem Biophys. 2012; 517:123-130. [PubMed: 22093699]

32. Ko KW, Erickson B, Lehner R. Es-x/Ces1 prevents triacylglycerol accumulation in McArdleRH7777 hepatocytes. Biochim Biophys Acta. 1791:1133-1143. [PubMed: 19651238] 
33. Zhao B, Natarajan R, Ghosh S. Human liver cholesteryl ester hydrolase: cloning, molecular characterization, and role in cellular cholesterol homeostasis. Physiol Genomics. 2005; 23:304310. [PubMed: 16131527]

34. Wei E, Ben Ali Y, Lyon J, Wang H, Nelson R, Dolinsky VW, Dyck JR, Mitchell G, Korbutt GS, Lehner R. Loss of TGH/Ces3 in mice decreases blood lipids, improves glucose tolerance, and increases energy expenditure. Cell Metab. 2010; 11:183-193. [PubMed: 20197051]

35. Wei E, Alam M, Sun F, Agellon LB, Vance DE, Lehner R. Apolipoprotein B and triacylglycerol secretion in human triacylglycerol hydrolase transgenic mice. J Lipid Res. 2007; 48:2597-2606. [PubMed: 17878493]

36. Jakubus T, Michalska-Jakubus M, Lukawski K, Janowska A, Czuczwar SJ. Atherosclerotic risk among children taking antiepileptic drugs. Pharmacol Rep. 2009; 61:411-423. [PubMed: 19605940]

37. Williams ET, Carlson JE, Lai WG, Wong YN, Yoshimura T, Critchley DJ, Narurkar M. Investigation of the Metabolism of Rufinamide and Its Interaction With Valproate. Drug Metab Lett. 2011 In press.

38. Kwan P, Brodie MJ. Phenobarbital for the treatment of epilepsy in the 21 st century: a critical review. Epilepsia. 2004; 45:1141-1149. [PubMed: 15329080]

39. Pustylnyak VO, Gulyaeva LF, Lyakhovich VV. CAR expression and inducibility of CYP2B genes in liver of rats treated with PB-like inducers. Toxicology. 2005; 216:147-153. [PubMed: 16153763]

40. Scheer N, Ross J, Rode A, Zevnik B, Niehaves S, Faust N, Wolf CR. A novel panel of mouse models to evaluate the role of human pregnane $X$ receptor and constitutive androstane receptor in drug response. J Clin Invest. 2008; 118:3228-3239. [PubMed: 18677425]

41. Surapureddi S, Rana R, Reddy JK, Goldstein JA. Nuclear receptor coactivator 6 mediates the synergistic activation of human cytochrome P-450 2C9 by the constitutive androstane receptor and hepatic nuclear factor-4alpha. Mol Pharmacol. 2008; 74:913-923. [PubMed: 18552123]

42. Vyhlidal CA, Gaedigk R, Leeder JS. Nuclear receptor expression in fetal and pediatric liver: correlation with CYP3A expression. Drug Metab Dispos. 2006; 34:131-137. [PubMed: 16243958]

43. Imai T. Human carboxylesterase isozymes: catalytic properties and rational drug design. Drug Metab Pharmacokinet. 2006; 21:173-185. [PubMed: 16858120]

\section{Abbreviation}

ТСРОВОР

CES

DMEM

GAPDH

HPLC

IS

PCN

RT-qPCR

\section{1,4-Bis[2-(3,5-dichloropyridyloxy)]benzene}

carboxylesterase

Dulbecco's modified eagle medium

glyceraldehyde-3-phosphate dehydrogenase

High-performance liquid chromatography

internal standard

pregnenolone 16a-carbonitrile

reverse transcription-quantitative polymerase chain reaction 
A

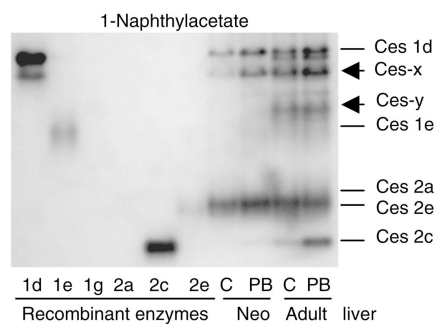

B

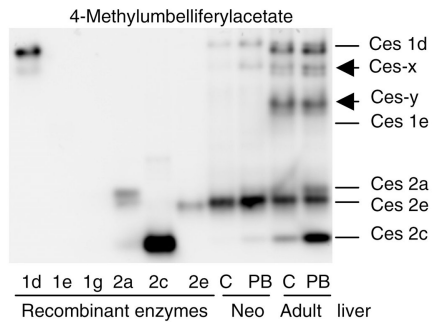

C

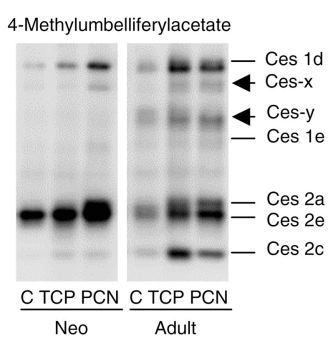

Fig. 1. Native-denaturing electrophoresis stained for hydrolytic activity of recombinant and native carboxylesterases

(A) Activity staining with 1-naphthylacetate Lysate $(10 \mu \mathrm{g})$ from carboxylesterasestransfected cells or liver homogenates $(10 \mu \mathrm{g})$ from neonates $(\mathrm{Neo})$ or adult mice treated with saline or phenobarbital were subjected to native gel electrophoresis and stained for esterase activity with 1-naphthylacetate as described in the section of Materials and Methods. Liver homogenates were pooled from control (C) or phenobarbital (PB)-treated mice $(n=4)$. (B) Activity staining with 4-methylumbelliferylacetate The experiment was performed as same as that with 1-naphthylacetate but stained with 4methylumbelliferylacetate. (C) Activity staining with 4-methylumbelliferylacetate in samples from TCPOBOP (TCP) or PCN (PCN)-treated mice Liver homogenates were pooled from control $(C)$, TCP or PCN-treated mice $(n=4)$ and analyzed for esterase activity with 4-methylumbelliferylacetate as described above. The staining intensity was captured by Carestream 2200 PRO Imager. This experiment was repeated four times. 
A

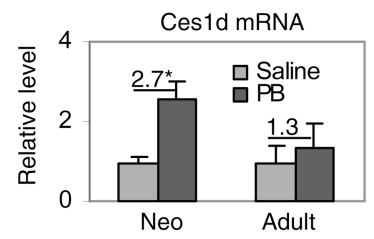

C

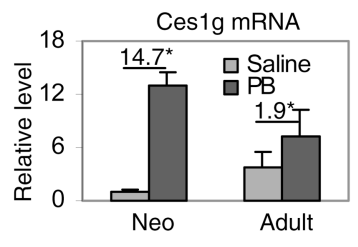

E

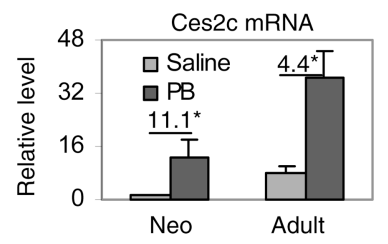

B

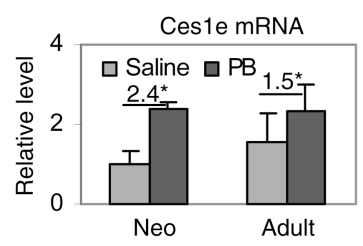

D

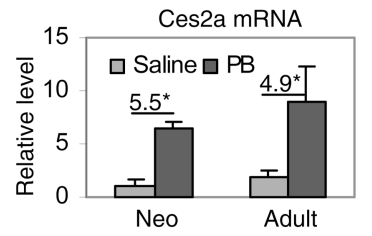

F

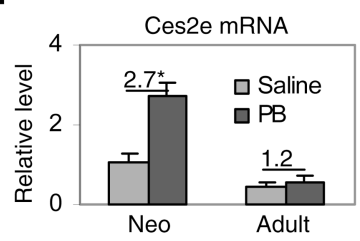

Fig. 2. Induction of carboxylesterase mRNA

Total liver RNA was isolated from mice treated with saline or phenobarbital (PB) and analyzed by RT-qPCR for the mRNA level of ces1d (A), ces1e (B), ces1g (C), ces2a (D), ces $2 \mathrm{c}(\mathrm{E})$ and ces $2 \mathrm{e}(\mathrm{F})$. Data were expressed as the mean \pm SD. The numeric numbers indicate the relative magnitude of induction and the asterisk sign denotes statistical significance $(P<0.05)$. 
A

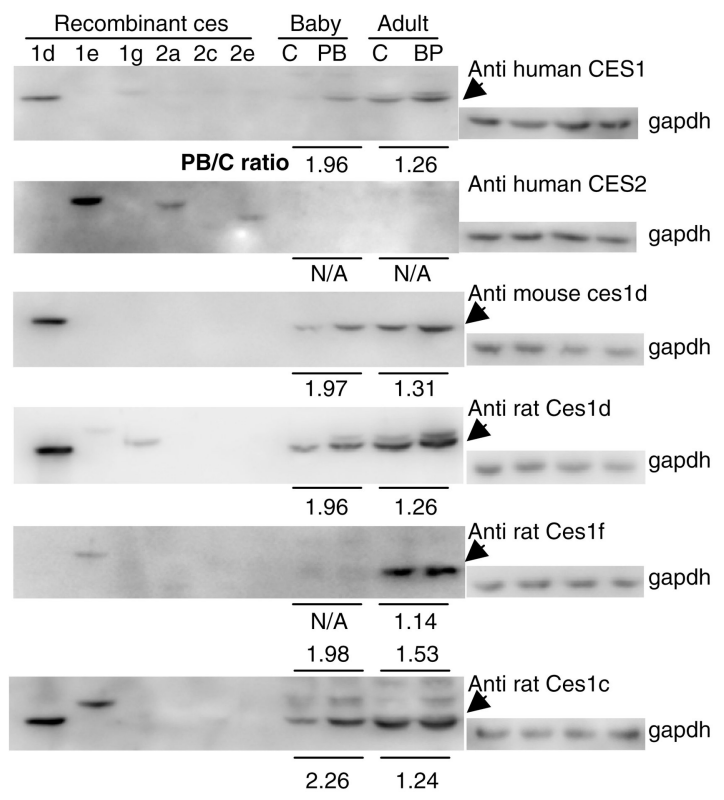

B
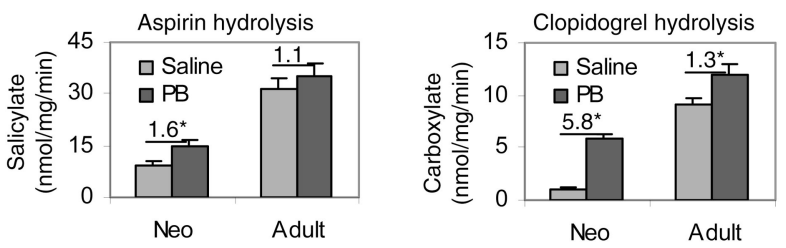

Fig. 3. Induction of carboxylesterase proteins

(A) Western blotting Lysate $(10 \mu \mathrm{g})$ from carboxylesterases-transfected cells or liver homogenates $(10 \mu \mathrm{g})$ from neonates $(\mathrm{Neo})$ or adult mice treated with saline or phenobarbital were resolved by $7.5 \%$ SDS-PAGE and transferred electrophoretically to nitrocellulose membranes. The blots were incubated with a carboxylesterase antibody and developed with chemiluminescent substrate and re-probed by gapdh antibody. The signal was captured by Carestream 2200 PRO Imager. The signals were normalized according to the signals from gapdh. The ratios indicate the relative signals of phenobarbital (PB) treatment over control (C). (B) Hydrolysis of aspirin and clopidogrel Enzyme incubations with S9 fraction $(20 \mu \mathrm{g})$ from individual livers $(n=4)$ were set up as described in Materials and Methods. The incubation for aspirin hydrolysis lasted for $60 \mathrm{~min}$ whereas only $20 \mathrm{~min}$ for clopidogrel hydrolysis. The formation of metabolites was determined by HPLC. Hydrolytic rates were expressed as the mean $\pm \mathrm{SD}$ ( $\mathrm{nmol}$ or $\mu \mathrm{mol} / \mathrm{mg} / \mathrm{min}$ ). The numeric numbers indicate the magnitude of increased hydrolysis over controls and the asterisk sign denotes statistical significance $(P<0.05)$. 

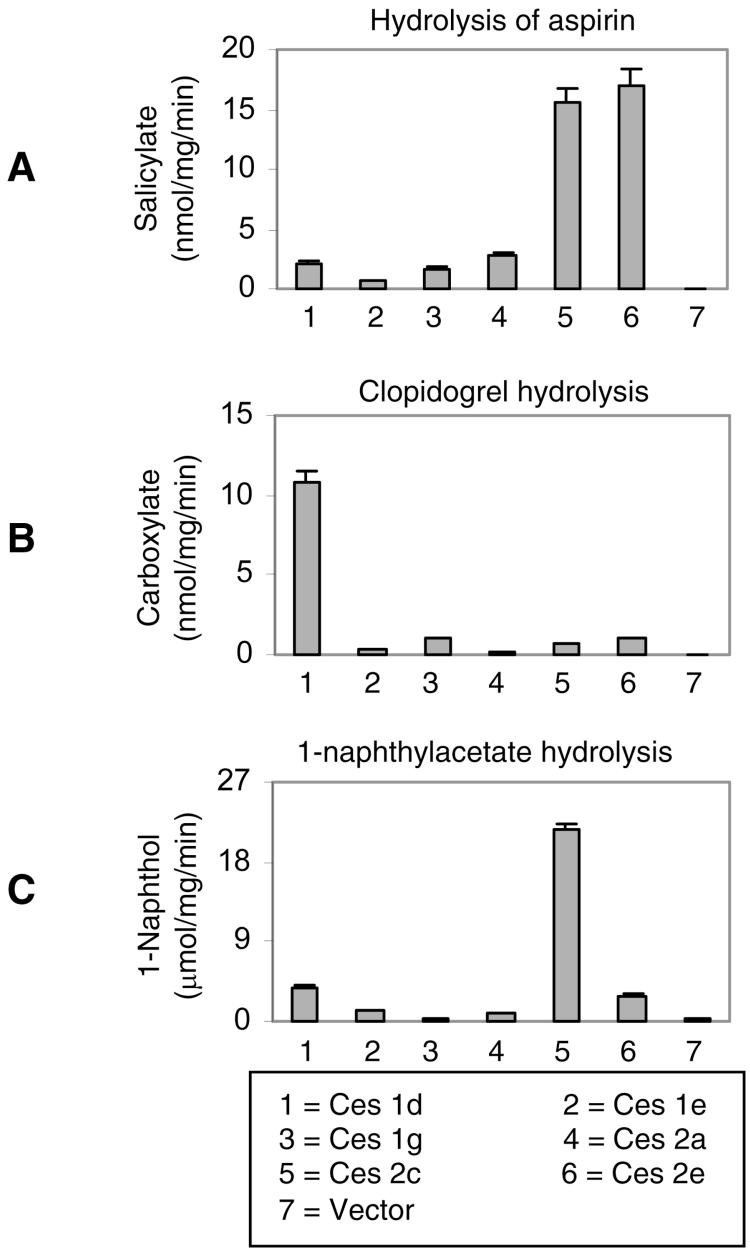

Fig. 4. Hydrolysis of aspirin, clopidogrel and 1-naphthylacetate by recombinant carboxylesterases

Cells (293T) were transfected with a carboxylesterase expression construct or the corresponding vector. The transfected cells were cultured for $24 \mathrm{~h}$ and cell lysates were prepared by sonication. Hydrolytic activity of cell lysates $(20 \mu \mathrm{g})$ was determined toward aspirin (A), clopidogrel (B) or 1-naphthylacetate (C). The hydrolysis of aspirin and clopidogrel was monitored by HPLC whereas the hydrolysis of 1-naphthylacetate by spectrophotometry from an increase in absorbance at $322 \mathrm{~nm}$ with $1 \mathrm{mM}$ 1-naphthylacetate. The results were collected from three separate experiments. The data are expressed as mean $\pm \mathrm{SE}$ (standard error). 

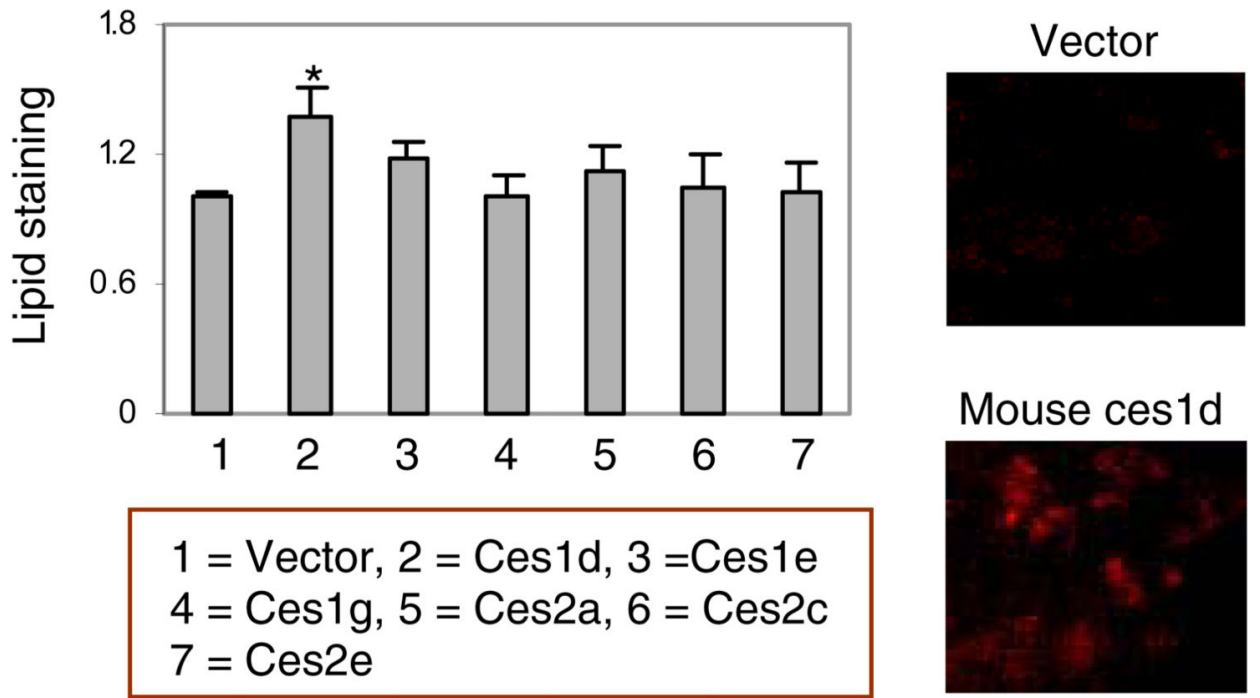

Fig. 5. Lipid staining by Oil Red O

Cells (293T) were transfected with a carboxylesterase expression construct or the corresponding vector. The transfected cells were cultured for $24 \mathrm{~h}$ and then cultured in fatty acid-rich medium. Cells were fixed and stained with Oil Red $\mathrm{O}$ as described in the section of Materials and Methods by microscopic or spectrophotometric analyses. The data are expressed as mean $\pm \mathrm{SE}$ (standard error). 